\title{
Trait-based representation of diatom functional diversity in a plankton functional type model of the eutrophied southern North Sea
}

\author{
N. Terseleer, ${ }^{1,}{ }^{*}$, a J. Bruggeman, ${ }^{2}$ C. Lancelot, ${ }^{1}$ and N. Gypens ${ }^{1}$ \\ ${ }^{1}$ Université libre de Bruxelles, Écologie des Systèmes Aquatiques, Brussels, Belgium \\ 2 Plymouth Marine Laboratory, The Hoe, Plymouth, United Kingdom
}

\begin{abstract}
We introduce a trait-based description of diatom functional diversity to an existing plankton functional type (PFT) model, implemented for the eutrophied coastal ecosystem in the Southern Bight of the North Sea. The trait-based description represents a continuum of diatom species, each characterized by a distinct cell volume, and includes size dependence of four diatom traits: the maximum growth rate, the half-saturation constants for nutrient uptake, the photosynthetic efficiency, and the relative affinity of copepods for diatoms. Through competition under seasonally varying forcing, the fitness of each diatom varies throughout time, and the outcome of competition results in a changing community structure. The predicted seasonal change in mean cell volume of the community is supported by field observations: smaller diatoms, which are more competitive in terms of resource acquisition, prevail during the first spring bloom, whereas the summer bloom is dominated by larger species which better resist grazing. The size-based model is used to determine the ecological niche of diatoms in the area and identifies a range of viable sizes that matches observations. The general trade-off between small, competitive diatoms and large, grazing-resistant species is a convenient framework to study patterns in diatom functional diversity. PFT models and trait-based approaches constitute promising complementary tools to study community structure in marine ecosystems.
\end{abstract}

Plankton functional type (PFT) models are considered powerful tools to describe the functioning of marine ecosystems (Le Quéré et al. 2005) and are used ubiquitously. The degree of sophistication of PFT models varies greatly, but they tend to increase in complexity over time in response to improved knowledge of species contribution to biogeochemical cycles and to new areas and scientific questions being addressed. Unfortunately, continued increasing complexity makes models difficult to constrain. Indeed, each addition of a new PFT needs parameterization of their physiological and ecological traits and validation data, which are often available in limited supply. As a result, continued addition of PFTs to models adds uncertainty and does not guarantee improvement of model skill (Hood et al. 2006).

Although PFT models recognize that some degree of functional diversity is necessary to describe biogeochemical processes properly, they omit a great part of this diversity by aggregating many different species or ecotypes in single PFTs. Conversely, recent adaptive modeling approaches emphasize plankton diversity by letting communities selfassemble through competition among large numbers of species or ecotypes (Bruggeman and Kooijman 2007; Follows et al. 2007). In these approaches, species are characterized by traits subject to observed or theoretical trade-offs. The relative performance, or fitness, of individual species is set by both their trait values (e.g., maximum growth rate, susceptibility to grazing) and the environment sensu lato (e.g., resource availability, presence of predators). Thus, the environment affects the outcome of

\section{* Corresponding author: ntersele@ulb.ac.be}

a Current address: Royal Belgian Institute of Natural Sciences, Operational Directorate Natural Environment, Brussels, Belgium interspecies competition. This is reflected in trait-based models: under variable forcing, the emergent community structure can show spatially or temporally varying species composition (e.g., seasonality, latitudinal gradients) in agreement with observations (Bruggeman and Kooijman 2007; Follows et al. 2007).

One phytoplankton class for which adaptive modeling approaches are particularly relevant is diatoms. Diatoms play a crucial role in marine ecosystems and ocean biogeochemical cycles (Sarthou et al. 2005). Accordingly, nearly all PFT models explicitly represent diatoms (Baretta et al. 1995; Lancelot et al. 2005; Le Quéré et al. 2005). These models generally lump all diatom species together into a single group with parameters representing an average diatom. However, diatoms show remarkable diversity that potentially affects the ecosystem structure and function. For instance, changes in the size structure of the diatom community induced by fertilization of iron-limited areas of the open ocean (Schartau et al. 2010) could have implications for both trophic interactions and carbon export (Boyd and Newton 1995). Such changes in diatom size structure are ubiquitous and have been reported along seasons (Widdicombe et al. 2010; Barton et al. 2013) and across aquatic ecosystems, with, for example, smaller species found in freshwater and larger in marine systems (Litchman et al. 2009). In a coastal area of the Southern Bight of the North Sea, intense monitoring of the diatom community composition showed strong variability with a clear seasonal component (Rousseau et al. 2002). In this area, several orders of magnitude separate the smallest observed diatom species (a few tens or hundreds of cubic micrometers; e.g., Asterionellopsis sp., Chaetoceros sp., Fragilaria sp.) from the largest ( $>10^{5}, 10^{6}$, or $10^{7} \mu \mathrm{m}^{3}$; e.g., Rhizosolenia sp., Guinardia sp., Coscinodiscus sp.). Because 
diatom size determines some of their functional traits (e.g., maximum growth rate, photosynthesis parameters; Sarthou et al. 2005), such seasonal variation is likely to affect ecosystem dynamics. Therefore, representation of diatom size diversity has the potential to improve model skill in a variety of applications.

In this study, we use an adaptive modeling approach to resolve the size structure of the diatom community in an existing PFT model, MIRO, for the continental shelf seas of the English Channel and Southern Bight of the North Sea (Lancelot et al. 2005). The MIRO model captures key elements of phytoplankton seasonal succession in this eutrophied area, notably, a massive bloom of Phaeocystis colonies occurring in late spring between two diatom blooms. To resolve diatom size structure, we modify MIRO's original diatom module to include size dependences for four diatom functional traits: maximum growth rate, nutrient affinity, photosynthetic efficiency, and susceptibility to grazing by copepods. The size dependences of these functional traits, based on a literature review of diatom-specific allometric relationships, indicate that diatom size is subject to a tradeoff, with resource limitation favoring small size and grazing pressure favoring large size. Under seasonal forcing including temperature, irradiance, and river inputs of nutrients, the size structure of the community is allowed to emerge through competition among diatom species of different sizes. The model is calibrated against a large data set that includes nutrient and biomass of several plankton types collected in the Belgian coastal zone (BCZ) between 1992 and 2000. The performance of the size-structured diatom module is evaluated by comparing the simulated mean and variance of diatom size to observations in the $\mathrm{BCZ}$. To understand more thoroughly diatom succession in this coastal ecosystem, we further investigate the contributions of different drivers (resource limitation, grazing) to changes in size and diversity. The potential of trait-based approaches to study ecological niches of phytoplankton (Litchman et al. 2012) is then exploited to evaluate the constraints that the $\mathrm{BCZ}$ ecosystem exerts on diatom size and, hence, community composition. The model is thus used to explain the observed succession and the absence of smaller or larger species in the area. Finally, the size-based description of diatom functional diversity is discussed and related to the ecological context of eutrophied marine systems based on the results obtained in this application.

\section{Methods}

The original model-The biogeochemical model MIRO (Lancelot et al. 2005) describes carbon (C), nitrogen (N), phosphorus $(\mathrm{P})$, and silicon $(\mathrm{Si})$ cycles through aggregated components of the planktonic and benthic realms of the coastal ecosystem of the English Channel and Southern Bight of the North Sea. Biological compartments of the model include three autotrophic (diatoms, nanoflagellates, and Phaeocystis globosa colonies) and three heterotrophic (microzooplankton, copepods, and bacteria) groups. Inorganic nutrients include nitrate and ammonium, which sum up to form the total dissolved inorganic N (DIN), dissolved inorganic P (DIP; i.e., phosphate) and dissolved Si (DSi).
The model is implemented in three successive homogeneous boxes (WCH, western channel; FCZ, French coastal zone; $\mathrm{BCZ}$ ) to take into account the accumulated nutrient enrichment of Atlantic waters by the Seine (FCZ) and Scheldt (BCZ) rivers. Each box is characterized by its own properties (e.g., depth, incident light, residence time; see table 1 in Lancelot et al. 2005) and is treated as an open system receiving waters from the adjacent box to the southwest and exporting water to the one located to the northeast (see fig. 1 in Lancelot et al. 2005). The WCH box produces boundary conditions representing Atlantic waters entering the area. The FCZ is mixed with $\mathrm{WCH}$ water (nutrients and carbon) introduced by advection and receives nutrients carried by the Seine. Finally, the BCZ is mixed with FCZ water and receives nutrients from the Scheldt.

Forcing-The model is run under interannual forcing for the 1992-2000 period. Variability in nutrient enrichment is accounted for by imposing monthly nutrient loads, as in Gypens et al. (2007): loads from the Seine were obtained from bimonthly measurements at the Caudebec downstream monitoring station; nutrient loads from the Scheldt were obtained from nutrient concentrations at the Doel station $\left(51^{\circ} 21^{\prime} 09^{\prime \prime} \mathrm{N}, 04^{\circ} 13^{\prime} 50^{\prime \prime} \mathrm{E}\right)$ and runoff at the upstream Schelle station that was corrected to include lateral freshwater inputs between Schelle and Doel (Rousseau et al. 2004). The residence time of water masses in the FCZ and BCZ boxes, which determines the extent of the mixing between boxes, is inversely related to the river discharges to account for the budget of the different masses (Atlantic waters and freshwater discharge), as in Lancelot et al. (2007). Forcing further includes the daily integrated surface incident photosynthetically active radiation, calculated from daily global solar radiation measured at the Oostende station of the Royal Institute of Meteorology in Belgium, as in Rousseau et al. (2002), and the daily seawater temperature estimated by a climatological mean (in the absence of measurements before 1995), as in Lancelot et al. (2005).

The trait-based diatom module-The original diatom module in MIRO was modified to introduce size dependencies of several processes. In addition to these modifications, which are described below, several changes were made to simplify the model: (1) the temperature dependence of diatom growth was set identical to that for the other phytoplankton groups in MIRO; (2) the silicon-to-carbon ratio of diatoms was made dependent on the external DSi concentration, as observed in Rousseau et al. (2002), following a Boltzmann sigmoidal function; (3) the detailed physiological processes governing the dynamics of the three internal pools of diatoms (DAs) in MIRO (small monomers, DAS; reserve material, DAR; and functional pool, DAF) were aggregated into a single-state equation for DAF (see below), with DAR and DAS estimated from DAF and the

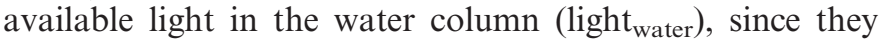
were well correlated in the original MIRO (the proportion of DAR to DAF is $0.0803+0.005 \times$ light $_{\text {water }}$ and the proportion of DAS to DAF is $0.0717+0.004 \times$ light $_{\text {water }}$ ); 4) the sedimentation and lysis rates of diatoms were set independent of the limitation by nutrients for simplicity, 


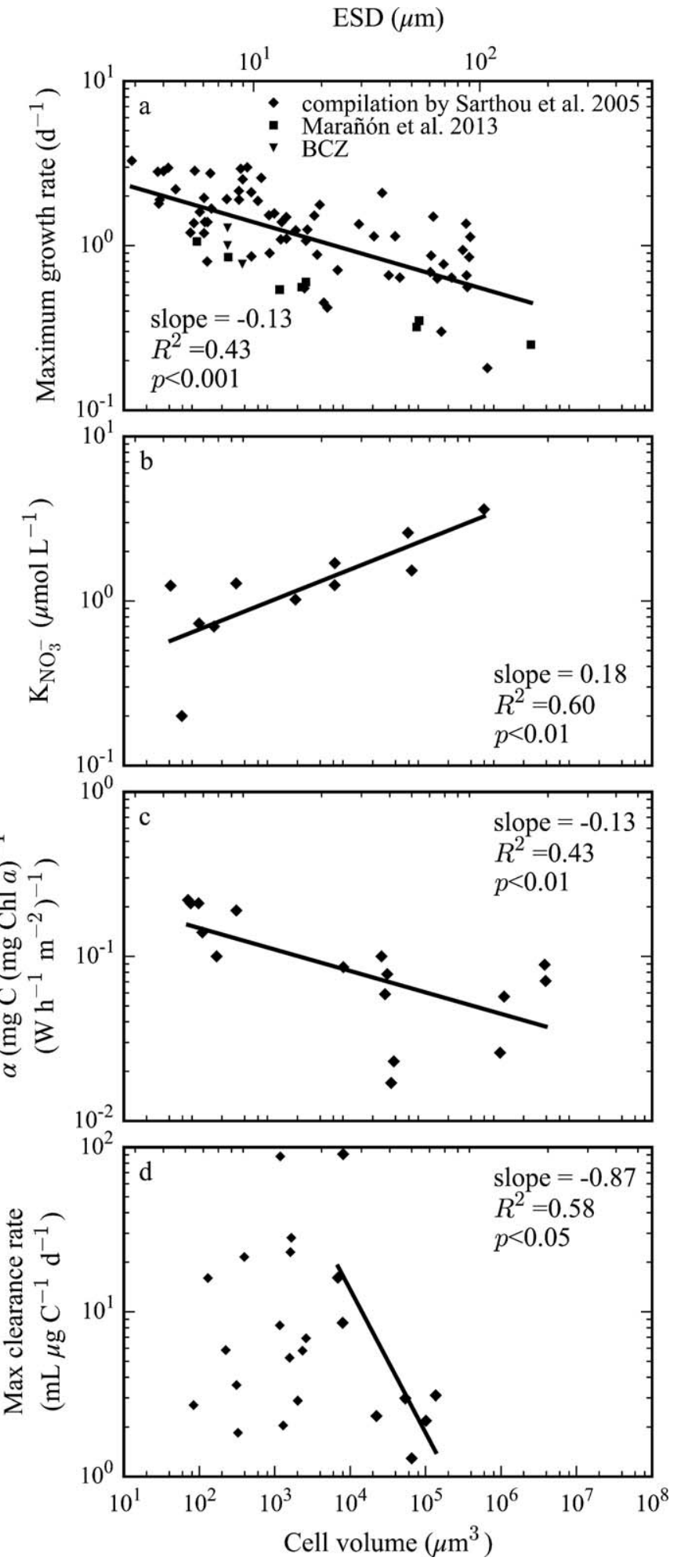

Fig. 1. Size dependency of major diatom functional traits: (a) $\mu_{\max }$ (review by Sarthou et al. 2005 and additional data from Marañón et al. 2013; V. Rousseau and J.-Y. Parent pers. comm. for the BCZ); (b) $K_{\mathrm{NO}_{3}}$ (review by Litchman et al. 2007); (c) $\alpha$ (data from Taguchi 1976); and (d) aff $\mathrm{DA}$ estimated from the maximum clearance rate of copepods on prey of different sizes (review by Gismervik et al. 1996). The allometric relationship for $a f f_{\mathrm{DA}}^{\mathrm{CP}}$ is estimated from data above the optimal prey size $(\sim 3 \times$ given the introduced size dependence of the half-saturation constants (see below). The original structure of MIRO and the trophic links are preserved: diatoms consume DIN and DIP in competition with nanoflagellates and Phaeocystis colonies; their growth also requires $\mathrm{Si}$; and they are grazed by copepods, which also feed on microzooplankton. A description of processes and parameters that are not directly involved in the dynamics of the modified diatom module described here is available in the appendix of the original paper (Lancelot et al. 2005).

Several functional traits of diatoms featured in the model are known to be size dependent. These include the maximum growth rate $\left(\mu_{\max }\right)$ the photosynthetic efficiency $(\alpha)$, the half-saturation constants for $\mathrm{N}$ uptake $\left(K_{\mathrm{N}}\right)$, and the relative affinity of copepods for diatoms $\left(a f f_{\mathrm{DA}}^{\mathrm{CP}}\right)$. Figure 1 shows the size dependences for these traits extracted from the literature. In line with previous studies relating phytoplankton traits to size (Litchman et al. 2007; Edwards et al. 2012), we describe these dependences with allometric relationships (i.e., power laws between traits and diatom cell volume $V$; linear in log-log space),

$$
\text { trait }=a \times V^{b}
$$

where $a$ and $b$ are two constants: the allometric constant $a$ (the exponential of the offset in log-log space) represents the reference value at a volume of $1 \mu \mathrm{m}^{3}$; the scaling exponent $b$ (the slope in log-log space, as in Fig. 1) sets the direction (positive or negative) and extent of the size dependency of each trait.

Figure 1a shows a negative allometric relationship for $\mu_{\max }$ in agreement with all previous compilations (see Finkel et al. 2010 for a recent review). Figure 1b shows the diatom-specific data extracted from $K_{\mathrm{N}}$ reviewed for different phytoplankton classes by Litchman et al. (2007). As a first approach, the same exponent as for $K_{\mathrm{N}}$ is assumed for $K_{\mathrm{P}}$ and $K_{\mathrm{Si}}$, assuming that comparable mechanisms determine their size dependence (e.g., related to the mass transfer coefficient and, thus, the cell radius; Aksnes and Egge 1991). Supporting this, a recent synthesis reported a positive and comparable exponent for $K_{\mathrm{N}}$ and $K_{\mathrm{P}}$ across marine phytoplankton (Edwards et al. 2012), and an early study on diatoms also suggested an increase in $K_{\mathrm{Si}}$ with increasing cell size (Paasche 1973). They are all globally referred to as half-saturation constants for nutrient uptake $\left(K_{\mathrm{NUT}}\right)$ in this paper and thus share the same exponent. Figure 1c reports measurements of the photosynthetic efficiency (i.e., the initial slope of photosynthesisirradiance curves) of diatoms across a wide range of sizes from Taguchi (1976). A same size dependence for the carbon-specific units in the model as for the chlorophyll $a$ (Chl $a$ )-normalized values in Fig. 1c is assumed: given the isometric scaling of the cellular content of carbon (Montagnes et al. 1994) and Chl $a$ (Montagnes et al. 1994; Marañón et al. 2007) with cell volume in phytoplankton,

$10^{3} \mu \mathrm{m}^{3}$ which is smaller than $>96 \%$ of the community mean cell volume measurements at the site of interest; see text for explanation). 
Table 1. Size dependency of major diatom traits from the literature: maximum growth rate $\left(\mu_{\max }\right)$, half-saturation constant for nutrient uptake $\left(K_{\mathrm{NUT}}\right)$, photosynthetic affinity $(\alpha)$, and relative affinity of copepods for diatoms $\left(a f f_{\mathrm{DA}}^{\mathrm{CP}}\right)$. Slopes $(\beta, \delta, \gamma$, $v)$, estimated from OLS regression, are presented along with the 95\% CIs, and the value used in the model after calibration.

\begin{tabular}{|c|c|c|c|c|c|}
\hline \multirow[b]{2}{*}{ Symbol } & \multirow[b]{2}{*}{ Parameter } & \multirow[b]{2}{*}{ Value } & \multicolumn{2}{|c|}{$95 \% \mathrm{CI}$} & \multirow{2}{*}{$\begin{array}{c}\text { Calibrated } \\
\text { value }\end{array}$} \\
\hline & & & Minimum & Maximum & \\
\hline$\beta$ & $K_{\mathrm{NUT}}$ & 0.18 & 0.071 & 0.29 & 0.072 \\
\hline$\delta$ & $\mu_{\max }$ & -0.13 & -0.17 & -0.096 & -0.15 \\
\hline$\gamma$ & $a f f_{\mathrm{DA}}^{\mathrm{CP}}$ & -0.87 & $-1.6^{*}$ & -0.13 & -0.37 \\
\hline v & $\alpha$ & -0.13 & -0.22 & -0.044 & -0.077 \\
\hline
\end{tabular}

* During optimization, this boundary was set to -0.6 . Inclusion of values below -0.6 greatly reduced the rate of convergence, while not affecting the ultimate result.

the $\mathrm{Chl}$ : $\mathrm{C}$ ratio can be considered constant across a wide range of sizes. Finally, Fig. 1d reports the copepod specific volumetric clearance rate compiled by Gismervik et al. (1996) as a function of prey size. Assuming a specific clearance rate independent of grazer size (Kiørboe 2011), the specific volumetric clearance rate reported in Fig. 1d is considered proportional to a constant maximum specific clearance rate, reached at optimal prey size $\left(\sim 3 \times 10^{3} \mu \mathrm{m}^{3}\right)$, and to the affinity for the prey, which depends on the prey size (with an affinity $=1$ at $\sim 3 \times 10^{3} \mu \mathrm{m}^{3}$ and lower at smaller or larger prey sizes). Figure $1 \mathrm{~d}$ hence reflects the size dependency of the copepod affinity for their prey, with a decreasing trend above $3 \times 10^{3} \mu \mathrm{m}^{3}$. Because this optimal size is smaller than $>96 \%$ of the reconstructed mean size observations in the $\mathrm{BCZ}$, only observations on prey larger than $3 \times 10^{3} \mu \mathrm{m}^{3}$ (large symbols) are included when deriving the allometric relationship (small symbols are omitted; Fig. 1d). As a consequence, a monotonic decrease of $a f f_{\mathrm{DA}}^{\mathrm{CP}}$ with increasing cell volume is used over the whole range of diatom size in the model. Thus, grazers drive selection toward large species (Smetacek 2001).

Table 1 summarizes the scaling exponents obtained from the relationships in Fig. 1 along with their 95\% confidence intervals (CIs). The size dependences of these functional traits were introduced in the trait-based diatom module illustrated in Fig. 2.

The size-dependent specific net growth rate of one diatom with a biomass $D A$ and a cell volume $V$ in the module is then

$$
\begin{aligned}
r(V)= & \mu_{\mathrm{max}}(V) \times f_{\mathrm{TEMP}}^{\lim } \times f_{\mathrm{NUT}}^{\lim }(V) \times f_{\mathrm{PAR}}^{\lim }(V) \\
& -g r a z_{\mathrm{DA}}^{\mathrm{CP}}(V)-k_{\mathrm{lys}} \times f_{\mathrm{TEMP}}^{\lim }-\frac{k_{\mathrm{sed}}}{z_{\mathrm{tot}}} \quad\left[h^{-1}\right]
\end{aligned}
$$

where $f_{\text {TEMP }}$ is the temperature response function (bellshaped with an optimal temperature $T_{\mathrm{opt}}=15^{\circ} \mathrm{C}$ and a width parameter $d T=12^{\circ} \mathrm{C}$ ); $f_{\mathrm{NUT}}^{\lim }$ and $f_{\mathrm{PAR}}^{\lim }$ are the limitation functions of diatom growth by nutrients and light, respectively; $g r a z_{\mathrm{DA}}^{\mathrm{CP}}$ is the grazing of diatoms by copepods; $k_{\mathrm{lys}}$ is the diatom lysis rate $\left(0.0016 \mathrm{~h}^{-1}\right) ; k_{\text {sed }}$ is their sedimentation rate $\left(0.0085 \mathrm{~m} \mathrm{~h}^{-1}\right)$; and $z_{\text {tot }}$ is the depth of the water column.

The size-dependent processes in Eq. 2 are formulated as follows,

$$
\begin{aligned}
& f_{\mathrm{NUT}}^{\lim }(V)= \\
& \frac{\mathrm{DIN} \times \mathrm{DIP} \times \mathrm{DSi}}{\left[K_{\mathrm{N}}(V) \times \mathrm{DIP} \times \mathrm{DSi}+K_{\mathrm{P}}(V) \times \mathrm{DIN} \times \mathrm{DSi}\right.} \quad[-] \\
& \left.+K_{\mathrm{Si}}(V) \times \mathrm{DIN} \times \mathrm{DIP}+\mathrm{DIN} \times \mathrm{DIP} \times \mathrm{DSi}\right] \\
& f_{\mathrm{PAR}}^{\lim }(V)=\frac{1}{z_{\mathrm{tot}}} \\
& \int_{0}^{z_{\text {tot }}}\left[1-\exp \left(-\operatorname{light}(z) \times \frac{\alpha(V)}{\mu_{\max }(V) \times f_{\text {TEMP }}^{\lim }}\right)\right] d z \quad[-] \\
& \operatorname{graz}_{\mathrm{DA}}^{\mathrm{COP}}(V)=g_{\mathrm{max}}^{\mathrm{CP}} \times f_{\mathrm{TEMP}}^{\text {lim }_{\mathrm{CP}}} \\
& \frac{\times a f f_{\mathrm{DA}}^{\mathrm{CP}}(V)}{\sum_{j}\left(a f f_{\mathrm{DA}_{j}}^{\mathrm{CP}}\left(V_{j}\right) \times D A_{j}\right)+\mathrm{MZ}+K_{\mathrm{CP}}} \times \mathrm{CP} \quad\left[\mathrm{h}^{-1}\right]
\end{aligned}
$$

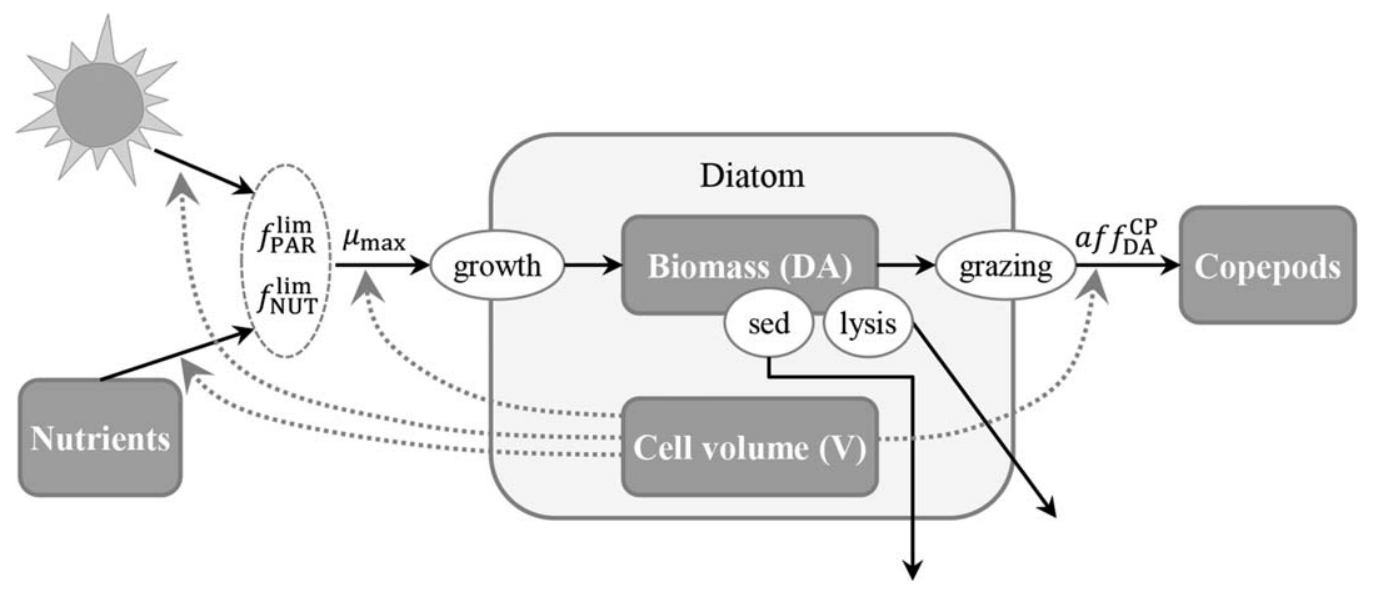

Fig. 2. The size-dependent diatom module in MIRO. State variables are shown as rounded boxes, and processes by arrows. Growth is limited by light $\left(f_{\mathrm{PAR}}^{\lim }\right)$ and nutrients $\left(f_{\mathrm{NUT}}^{\lim }\right)$. Nutrients include DIN, DIP, and DSi. Dotted arrows show the control of diatom cell volume on growth and loss processes. In addition to the size-dependent growth and grazing processes, diatom losses include lysis and sedimentation (sed). 
Table 2. Optimized parameters ( $v_{\text {NEW }}$, calibrated between minimum [Min] and maximum [Max] values) and comparison with the original value ( $v_{\text {MIRO }}$ ) when it existed in MIRO (Lancelot et al. 2005).

\begin{tabular}{|c|c|c|c|c|c|c|}
\hline Symbol & Parameter & Unit & $v_{\text {MIRO }}$ & Min & Max & $v_{\mathrm{NEW}}$ \\
\hline$\beta$ & Size scaling exponent of $K_{\mathrm{NUT}}$ & - & - & 0.071 & 0.29 & 0.072 \\
\hline$\delta$ & Size scaling exponent of $\mu_{\max }$ & - & - & -0.17 & -0.096 & -0.15 \\
\hline$\gamma$ & Size scaling exponent of $a f f_{\mathrm{DA}}^{\mathrm{CP}}$ & - & - & -0.6 & -0.13 & -0.37 \\
\hline$v$ & Size scaling exponent of $\alpha$ & - & - & -0.22 & -0.044 & -0.077 \\
\hline$K_{\mathrm{N}}^{\mathrm{ref}}$ & Half-saturation constant for $\mathrm{N}$ at $2 \times 10^{4} \mu \mathrm{m}^{3}$ & mmol $\mathrm{N} \mathrm{m}^{-3}$ & 0.8 & 0.7 & 0.9 & 0.84 \\
\hline$K_{\mathrm{P}}^{\mathrm{ref}}$ & Half-saturation constant for $\mathrm{P}$ at $2 \times 10^{4} \mu \mathrm{m}^{3}$ & $\mathrm{mmol} \mathrm{P} \mathrm{m}^{-3}$ & 0.3 & 0.2 & 0.4 & 0.24 \\
\hline$\stackrel{\stackrel{r}{r e f}}{\mathrm{Si}^{2}}$ & Half-saturation constant for Si at $2 \times 10^{4} \mu \mathrm{m}^{3}$ & $\mathrm{mmol} \mathrm{Si} \mathrm{m}{ }^{-3}$ & 0.4 & 0.7 & 0.9 & 0.83 \\
\hline$\mu_{\mathrm{max}}^{\mathrm{sl}}$ & Maximum growth rate at $2 \times 10^{4} \mu \mathrm{m}^{3}$ & $\mathrm{~h}^{-1}$ & 0.05 & 0.025 & 0.075 & 0.075 \\
\hline aff $\mathrm{CP}_{\mathrm{Pef}}$ & Copepod relative affinity for a diatom at $2 \times 10^{4} \mu \mathrm{m}^{3}$ & - & 1 & 0.5 & 2 & 1.2 \\
\hline$\alpha^{\mathrm{ref}}$ & Photosynthetic efficiency at $2 \times 10^{4} \mu \mathrm{m}^{3}$ & $\mathrm{~h}^{-1}\left(\mu \mathrm{mol} \text { quanta } \mathrm{m}^{-2} \mathrm{~s}^{-1}\right)^{-1}$ & - & 0.002 & 0.004 & 0.004 \\
\hline $\mathrm{Si}: \mathrm{C}_{\min }$ & Minimum $\mathrm{Si}: \mathrm{C}$ ratio of diatoms & mol Si : mol C & 0.11 & 0.048 & 0.24 & 0.066 \\
\hline $\mathrm{Si}: \mathrm{C}_{\max }$ & Maximum $\mathrm{Si}: \mathrm{C}$ ratio of diatoms & mol Si: mol C & 0.36 & 0.48 & 0.78 & 0.72 \\
\hline$D S i_{\text {infl }}$ & DSi concentration where $\mathrm{Si}: \mathrm{C}=\left(\mathrm{Si}: \mathrm{C}_{\max }-\mathrm{Si}: \mathrm{C}_{\min }\right) / 2$ & $\mathrm{mmol} \mathrm{Si} \mathrm{m}{ }^{-3}$ & - & 5 & 8 & 5.1 \\
\hline $\mathrm{g}_{\max }^{\mathrm{CP}}$ & Maximum grazing rate of copepods & $\mathrm{h}^{-1}$ & 0.04 & 0.03 & 0.05 & 0.032 \\
\hline$K_{\mathrm{CP}}$ & Half-saturation constant for prey consumption of copepods & $\mathrm{mmol} \mathrm{C} \mathrm{m}{ }^{-3}$ & 50 & 40 & 60 & 40 \\
\hline$v_{\text {init }}$ & Initial variance & $\left(\log \mu \mathrm{m}^{3}\right)^{2}$ & - & 0 & 12 & 2.8 \\
\hline$v_{\text {in }}$ & Import variance & $\left(\log \mu \mathrm{m}^{3}\right)^{2}$ & - & 0 & 12 & 7.0 \\
\hline & Relaxation rate & $\mathrm{h}^{-1}$ & - & 0 & 0.001 & 0.00093 \\
\hline$K_{\mathrm{P}}^{\text {Phaeo }}$ & Half-saturation constant for $\mathrm{P}$ of Phaeocystis* & $\mathrm{mmol} \mathrm{P} \mathrm{m}^{-3}$ & 0.001 & 0.001 & 0.1 & 0.021 \\
\hline
\end{tabular}

* Optimized to enhance stability during the optimization process to avoid crashes due to a too small $K_{\mathrm{P}}^{\text {Phaeo }}$ values. No effect on model results.

where $\operatorname{light}(z)$ is the light in the water column at depth $z$; $g_{\max }^{\mathrm{CP}}$ is the maximum grazing rate of copepods at optimal temperature; $f_{\mathrm{TEMP}}^{\lim \mathrm{CP}}$ is the temperature response function of copepods; $K_{\mathrm{CP}}$ is the half-saturation constant of copepods for the consumption of diatoms and microzooplankton; $\mathrm{MZ}$ and $\mathrm{CP}$ are the biomass of microzooplankton and copepods, respectively; and $j$ is the index of all other diatoms in the community. The summation in Eq. 5 is estimated by Taylor expansion up to the second order. The terms involving sizedependent traits $\left(\mu_{\max }, K_{\mathrm{NUT}}, \alpha\right.$, and $\left.a f f_{\mathrm{DA}}^{\mathrm{CP}}\right)$ simply include the formulation of these parameters given by Eq. 1. Values of the different parameters (after optimization, see the "Model calibration" section below) are reported in Table 2 .

Community approximation - Rather than explicitly representing each diatom species (each requiring one state variable; Bruggeman et al. 2007; Follows et al. 2007), a continuum of diatom types (each characterized by biomass $D A_{i}$ and cell volume $V_{i}$ ) is approximated by the community-integrated biomass, mean cell volume, and variance in cell volume (i.e., a measure of diversity). The dynamics of these statistics are described with a moment-based approximation (Wirtz and Eckhardt 1996; Norberg et al. 2001; Merico et al. 2009), using a Gaussian closure (i.e., skewness is zero, kurtosis is $3 \times$ variance $^{2}$ ). This approximation achieves maximum accuracy if the probability distribution of the model trait (cell volume here) is symmetric around the mean and - only for the variance - close to Gaussian. Investigation of the data showed that the distribution of cell volume is skewed toward larger values and that log transformation was needed to satisfy this requirement (not shown). Approximate dynamics of the total diatom biomass $(D A)$, the mean of the log cell volume $(\bar{\omega})$, and its variance $(v)$ are then given by (Wirtz and Eckhardt 1996; Norberg et al. 2001; Merico et al. 2009),

$$
\begin{gathered}
\frac{d D A}{d t} \approx D A \times\left[r(\bar{\omega})+\frac{1}{2} v \frac{\partial^{2} r(\bar{\omega})}{\partial \omega^{2}}\right] \quad\left[\mathrm{mg} \mathrm{C} \mathrm{m}^{-3} \mathrm{~h}^{-1}\right] \\
\frac{d \bar{\omega}}{d t} \approx v \frac{\partial r(\bar{\omega})}{\partial \omega} \quad\left[\log \mu \mathrm{m}^{3} \mathrm{~h}^{-1}\right] \\
\frac{d v}{d t} \approx v^{2} \frac{\partial^{2} r(\bar{\omega})}{\partial \omega^{2}} \quad\left[\left(\log \mu \mathrm{m}^{3}\right)^{2} \mathrm{~h}^{-1}\right]
\end{gathered}
$$

where $r(\bar{\omega})$ is the specific net growth rate of a diatom (Eq. 2) evaluated at $\omega=\bar{\omega}$ (with $\omega=\log V$ ). Simulations with Eqs. 6-8 indicate that, as in other studies (Norberg et al. 2001), the variance cannot be sustained through Eq. 8 alone: $v$ drops to zero, leaving a single-size diatom community incapable of adaptation $(d \bar{\omega} / d t=0)$. Such competitive exclusion is a common phenomenon in models and usually attributed to unresolved processes, such as spatiotemporal heterogeneity, interspecific interaction, density-dependent mortality (e.g., viruses), or the presence of resting stages (Chesson 2000). Rather than arbitrarily including any of these mechanisms, we parameterize their effect on diatom diversity by prescribing continuous immigration of a diatom community that has the same mean cell volume as the resident community (no effect on $\bar{\omega})$, a negligible biomass $\left(D A_{\text {in }}\right.$ is less than a thousandth of the resident community biomass $D A$ ), and a variance $v_{i n}$. The effect on the resident variance $v$ is given through the addition of $r_{v a r}\left(v_{\text {in }}-v\right)$ to Eq. 5 (Norberg et al. 2001), where $r_{v a r}$ is the relaxation rate $\left(=D A_{\text {in }} / D A \times \mathrm{h}^{-1}\right.$, calibrated between 0 [no incoming community] and 
$0.001 \mathrm{~h}^{-1}$; Table 2). Such an immigrant community would, for instance, mimic the seeding by benthic resting diatoms, a process known to affect bloom development and composition (McQuoid and Godhe 2004). This local seeding is superimposed on the immigration and export resulting from physical mixing between boxes that affects diatom biomass, mean cell volume, and variance simulated in the three boxes.

Model calibration - Because the original diatom module is significantly modified to include size dependences, all parameters closely associated with diatom dynamics (Table 2) are calibrated against data available in the $\mathrm{BCZ}$ between 1992 and 2000. The data set includes concentration of DIN, DIP, and DSi, as well as biomass of diatoms, nanoflagellates, Phaeocystis, copepods, microzooplankton, and bacteria. Data for diatoms, Phaeocystis, and nutrients were collected on a weekly or biweekly basis throughout 1992-2000. Available data for nanoflagellates are limited to spring months in 1993, 1994, 1996, 1998, and 1999, and data for microzooplankton and bacteria are available in 1993, 1994, and 1996 (spring) and in 1998 (whole year). Finally, data for copepods are available only in 1999 and 2000 (essentially in spring, with some observations in summer). The diatom data set includes counting and identification up to the species levels of 68 taxa. Their biovolumes were calculated and converted into carbon biomass using the carbon-to-volume relationship for diatoms of Menden-Deuer and Lessard (2000). These values were used here to compute the biomass-weighted mean and variance of the cell volume of the diatom community as validation data. Because the present study focuses on the mean seasonality of diatom size structure, model results over 1992-2000 are averaged into a 1-yr climatology.

The range explored during the optimization process and the resulting values are given in Table 2. The ranges for allometric exponents are the $95 \%$ CIs from ordinary least squares (OLS) regression reported in Table 1, except for $\gamma$ (exponent of aff $f_{\mathrm{DA}}^{\mathrm{CP}}$ ) because preliminary investigations showed that the steepest part of the range was not selected for but greatly reduced the rate of convergence. Discussion exists on whether OLS or reduced major axis (RMA) regression should be used to derive the line of best fit of allometric relationships (Smith 2009). Both are used in phytoplankton ecology (Finkel 2001; Litchman et al. 2007; Edwards et al. 2012). No severe effects on the results presented here are expected if using RMA CIs instead of OLS CIs in the optimization. The ranges for the other parameters (including the allometric constants) were set as a function of the original values in MIRO to avoid a complete change in model behavior (see Table 2).

The algorithm used for calibration is Differential Evolution, which is known for its robustness and straightforward parallelization (Storn and Price 1997). The three control variables of this algorithm were set following the recommendations in Storn and Price (1997) and with the intention to speed up the optimization process: the size of the population was set to six times the number of parameters to optimize, the weighting factor was set to
0.5 , and the crossover constant was set to 0.9. The optimization criterion was the maximum log likelihood, assuming a normal distribution of residuals, with variablespecific standard deviations (i.e., separate standard deviations for DIN, DIP, diatom biomass, etc.) that were estimated simultaneously with the model parameters. Differential Evolution was coded and implemented in Fortran, and parallelization was done using the Message Passing Interface protocol on the clusters of the Consortium des Équipements de Calcul Intensif (CÉCI) and of the Computing Centre High Performance Computing of the Université libre de Bruxelles-Vrije Universiteit Brussel (ULB-VUB). The optimization process reached $>2.5 \times$ $10^{5}$ model runs.

\section{Results}

Calibration: nutrients and biomass - Model results for the biomass of autotrophs (diatoms, Phaeocystis colonies, nanoflagellates) and heterotrophs (copepods, microzooplankton, bacteria) and nutrient (DIN, DIP, DSi) concentrations are shown in Fig. 3. As in the original MIRO (Lancelot et al. 2005), the model reproduces the main features of the plankton dynamics in the area. The time evolution of the diatoms is characterized by two blooms (spring and summer) of comparable levels $(\sim 165-$ $180 \mathrm{mg} \mathrm{C} \mathrm{m}^{-3}$ ) but distinct in duration (Fig. 3a). Overall, the timing of the peaks, initial growth, and final decline of the vegetative period is good; yet, the model simulates a slightly too abrupt decline of the first bloom and early development of the second bloom ( $\sim 1$ month). A massive $\left(>1000 \mathrm{mg} \mathrm{C} \mathrm{m}^{-3}\right.$ ) and short-lived ( $\sim 7$ weeks) bloom of Phaeocystis colonies is simulated from day 100 , between the two diatom blooms, and characterizes this eutrophied coastal ecosystem (Fig. 3b). The third autotrophic group is of lesser importance in terms of biomass: nanoflagellates are $<50 \mathrm{mg} \mathrm{C} \mathrm{m}{ }^{-3}$ in spring in both data and model (Fig. 3c). The model simulates additional nanoflagellate blooms in autumn, with a high interannual variability. In the absence of data for that time period, the optimization does not constrain these blooms, but because they often reach higher biomass than during the typical spring bloom, while additionally stimulating microzooplankton regrowth not supported by observations (Fig. 3i), we view these secondary blooms as unlikely to occur in reality. Fortunately, the effect of this secondary nanoflagellate bloom on model behavior is limited: it does not reach beyond moderate stimulation of microzooplankton growth and perhaps slightly underestimates diatom levels at the end of the year (Fig. 3a).

Nutrient concentrations are the result of biotic (consumption, remineralization) and abiotic (continental loads and inflow-outflow) processes. In agreement with observations, modeled winter DSi reaches $\sim 12 \mathrm{mmol} \mathrm{m}^{-3}$ before its consumption in early spring by the first diatom bloom (Fig. 3d). DSi is then maintained at low levels $\left(<3 \mathrm{mmol} \mathrm{m}^{-3}\right)$ in both data and model before the stocks rebuild during autumn-winter. In between the two diatoms blooms, DSi shows a slight increase from remineralization. DIN reaches winter levels up to $40 \mathrm{mmol} \mathrm{m}^{-3}$ (both in data 

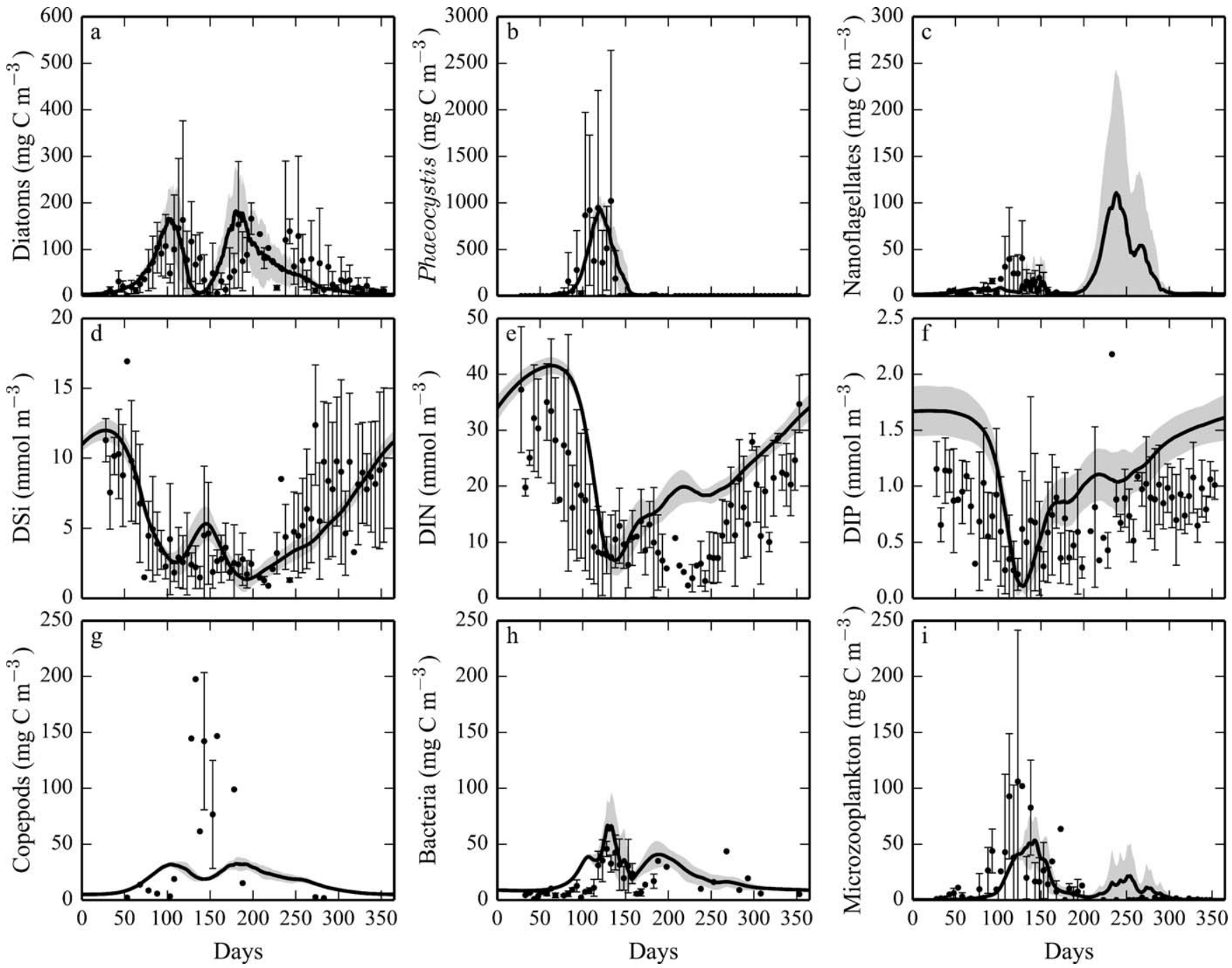

Fig. 3. Seasonal evolution of the modeled biomass and nutrients compared with observations for 1992 to 2000: (a) diatoms, (b) Phaeocystis colonies, (c) nanoflagellates, (d) DSi, (e) DIN, (f) DIP, (g) copepods, (h) bacteria, (i) microzooplankton. Solid lines represent the interannual average of model results and shaded areas the corresponding standard deviation (SD). Dots indicate the mean of all 19922000 samples that fall within the same 5-d window; error bars represent the corresponding SD.

and model; Fig. 3e) because of river inputs and is never limiting diatom growth in the area. The first drawdown in spring is properly captured by the model, but the model fails to reproduce the summer depletion in DIN. DIP concentrations show variations of lower amplitude in the data than in the model, which globally overestimates DIP levels $\left(>1 \mathrm{mmol} \mathrm{m}^{-3}\right.$ except during the depletion episode due to the Phaeocystis bloom; Fig. 3f).

Among heterotrophs, copepods (Fig. 3g) are less well represented by the model, although the lack of data (19992000 only) prevents an optimal calibration and a better assessment of the model skills regarding copepods. Their time evolution in the model is essentially controlled by the two simulated diatom blooms that they closely follow. The simulated levels are underestimated and never reach $40 \mathrm{mg} \mathrm{C} \mathrm{m} \mathrm{m}^{-3}$, while the data report concentrations $>200 \mathrm{mg} \mathrm{C} \mathrm{m}^{-3}$. This shortcoming was already observed in the original MIRO (Lancelot et al. 2005) and is attributed to the inherent limitation of the structure of MIRO where copepods are a closure term (Lancelot et al. 2005). Finally, bacteria and microzooplankton are reasonably well represented by the model (Fig. $3 \mathrm{~h}$ and $3 \mathrm{i}$, respectively). The former reach their maximal value $\left(\sim 70 \mathrm{mg} \mathrm{C} \mathrm{m}^{-3}\right)$ in spring but are continuously present $\left(>10 \mathrm{mg} \mathrm{C} \mathrm{m}^{-3}\right)$ during the growing season, whereas the latter reach $\sim 55 \mathrm{mg} \mathrm{C} \mathrm{m}^{-3}$ more locally after their bacterial and nanoflagellate prey have increased in concentration (i.e., after day 100).

Emergent diatom community structure: Mean cell volume and variance-With the trait-based representation of diatoms in MIRO, two new state variables are introduced to describe the whole community: the mean cell volume of the diatom community and its variance (i.e., a measure of the size diversity in the diatom community). Their time evolution is compared with observations in Fig. 4.

Although the model has not been calibrated against these observations, there is a good agreement between the modeled and observed trends in diatom mean cell volume. 

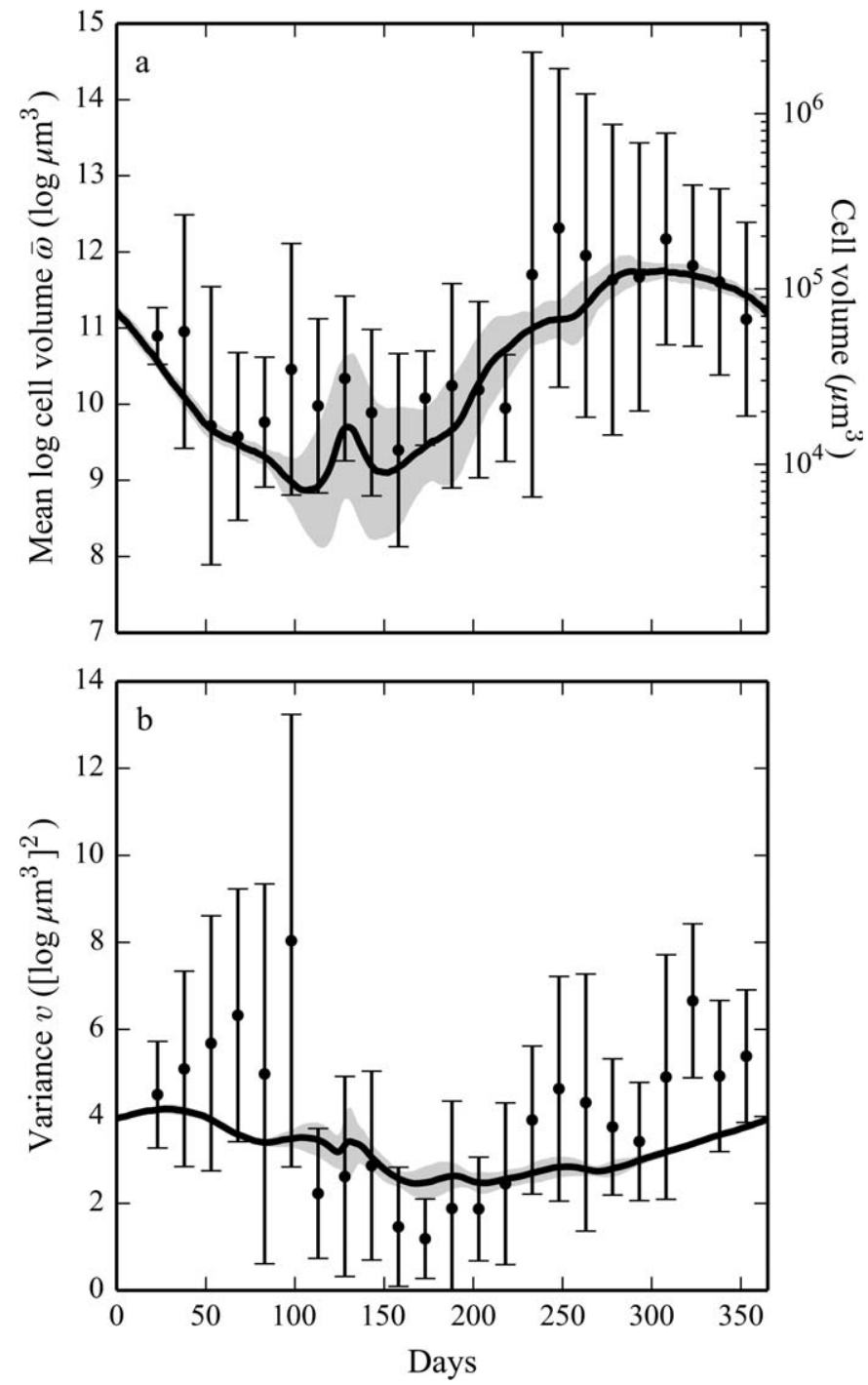

Fig. 4. Seasonal evolution of (a) the mean cell volume and (b) variance predicted by the model, compared with observations, for 1992-2000. Solid lines represent the interannual average of model results and shaded areas the corresponding SD. Dots indicate the mean of all 1992-2000 samples that fall within the same 15-d window; error bars represent the corresponding $\mathrm{SD}$.

Overall, the modeled diatom spring bloom is composed of smaller species, and the summer bloom has a larger mean cell volume, as observed (Fig. 4a). Detailed examination of the time evolution of the mean cell volume suggests successive stages. At the beginning of the year (days 1$100)$, the relatively large mean cell volume observed and modeled for the winter community decreases to reach a minimum $\left(\sim 10^{4} \mu \mathrm{m}^{3}\right.$; Fig. 4a) during the first part of the spring diatom bloom (Fig. 3a). Relatively low mean cell volumes $\left(<3 \times 10^{4} \mu \mathrm{m}^{3}\right)$ with a moderate increase are then simulated and observed between spring and early summer (days 100-200, Fig. 4a; i.e., during the transition from the spring to summer diatom bloom; Fig. 3a). The second part of the summer bloom is characterized by a steeper increase in the mean cell volume to reach a maximum

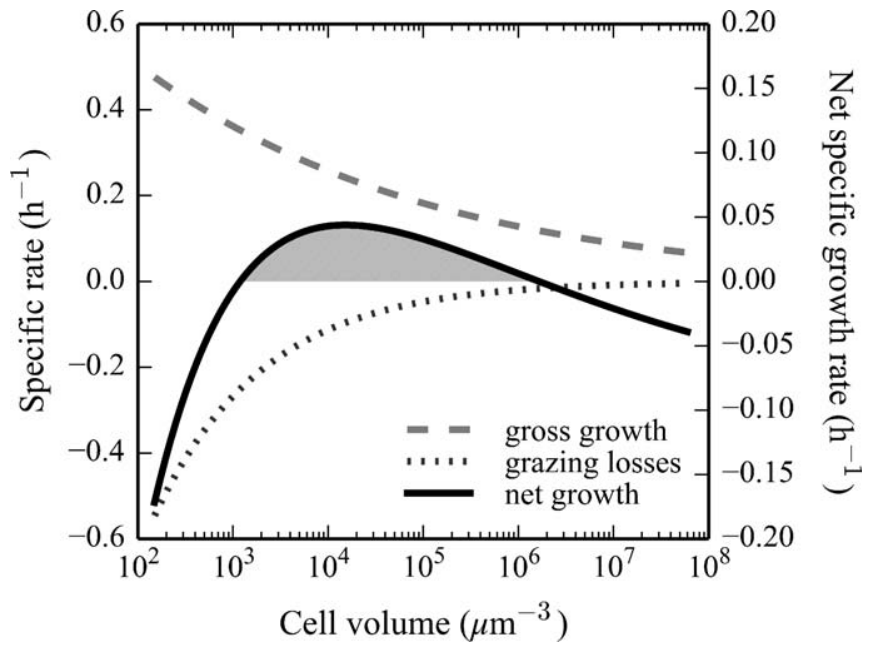

Fig. 5. Size dependence in the model of the specific growth rate (dashed line; left axis), the specific grazing loss rate (dotted line, left axis), and the net specific growth rate (continuous line, right axis) at day 75 . The hatched shaded area indicates the area of positive net growth. The net specific growth rate results from the sum of the specific growth and grazing rates and includes sizeindependent loss rates due to sedimentation and lysis (not shown).

$\left(\sim 10^{5} \mu \mathrm{m}^{3}\right)$ in early autumn (days $\left.200-300\right)$, in agreement with observations.

The general time evolution of the variance is properly caught by the model and is characterized by higher values at the beginning and end of the year in both the model and data (Fig. 4b). Its average value corresponds to observations, but the simulated amplitude of changes in variance is however too small compared with data. Quantitative differences between predicted and observed variance are to be expected, however, because the approximation of its dynamics (Eq. 8) is less accurate than that of the total biomass and mean (specifically, the variance approximation depends on the assumption of a symmetrical size distribution; Norberg et al. 2001) and because of the simple parameterization of diversity-restoring processes. In view of these limitations, the qualitative similarity between predicted and observed variance trajectories, and the comparable time-averaged values, are encouraging.

Factors controlling the diatom size structure-What drives the evolution of the diatom size distribution? The four size-dependent traits introduced in the model $\left(\mu_{\max }, \alpha\right.$, $K_{\mathrm{NUT}}$, and $\left.a f f_{\mathrm{DA}}^{\mathrm{CP}}\right)$ imply that the source and sink terms of diatoms are dependent on their cell volume. To illustrate this, Fig. 5 shows the value of the specific rates of gross growth and grazing losses (both in Eq. 2) in the growth phase of the first bloom (day 75) as a function of cell volume. Bottom-up pressures decrease gross growth with increasing cell volume (Fig. 5), which favors small size. Conversely, top-down pressures increase grazing losses (i.e., they decrease net growth) with decreasing cell volume (Fig. 5), favoring large size. The sum of the size-dependent gross growth and grazing losses (in addition to the sizeindependent lysis and sedimentation losses) equals the net specific growth rate (black line in Fig. 5), which reaches a 


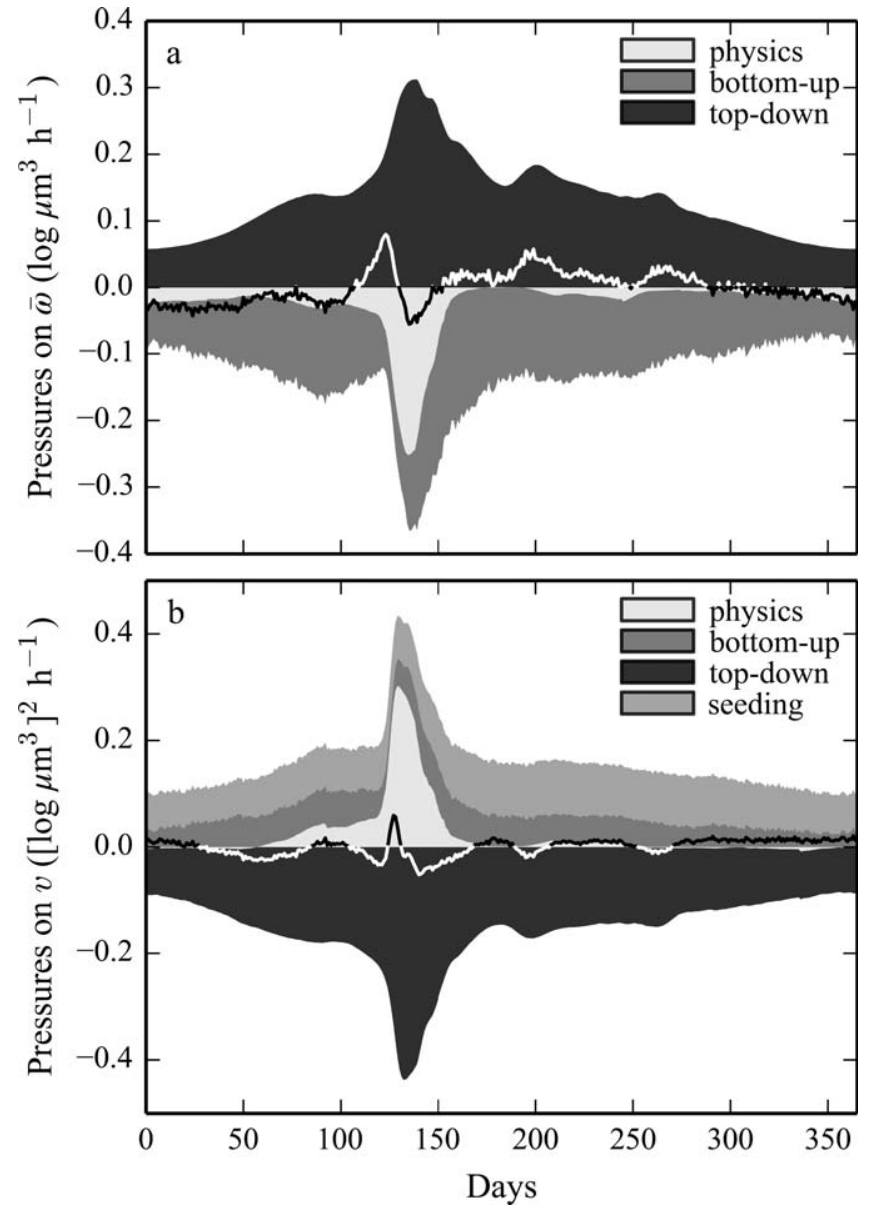

Fig. 6. Seasonal evolution of the pressures on (a) the mean cell volume and (b) variance. In panel $\mathrm{a}$, the resulting balance between upward and downward pressures is shown as a white and black line for positive and negative values, respectively. In panel b, the resulting balance between upward and downward pressures is shown as a black and white line for positive and negative values, respectively.

maximum at intermediate size. The position of this maximum is a function of the environmental constraints (bottom-up and top-down pressures); therefore, it is the optimal cell volume under the current conditions. Under variable forcing, the position of the optimum changes over time. Simultaneously, the range of diatom sizes that experience net growth (hatched shaded area in Fig. 5) will vary.

At any point in time, the size sensitivity of net specific growth (black line in Fig. 5) dictates the change in community size structure: if sizes larger than the current mean achieve a higher growth rate, the mean size will increase; if sizes smaller than the current mean achieve a higher growth rate, the mean size will decrease. This is reflected by the dynamic equation for the mean size (Eq. 7), which is controlled by the first derivative of the net specific growth rate. Similarly, the width of the fitness optimum determines the rate at which diversity declines: a narrow, sharp peak causes strong selection and rapid diversity decline, whereas a broad peak reduces selection and preserves diversity longer. This behavior is reflected by the dynamic equation for the variance (Eq. 8), which is controlled by the second derivative of the net specific growth rate. It is possible to disentangle contributions of bottom-up (gross growth) and top-down (grazing loss) control to the change in the mean and variance of diatom size. This is shown in Fig. 6 as pressures acting on the mean (Fig. 6a) and variance (Fig. 6b) of diatom cell volume over time. Additionally, the effect of physical inflow-outflow from the $\mathrm{BCZ}$ is shown, as well as the immigrating community used to restore variance (Fig. 6b only).

Small diatoms are more competitive in terms of resource acquisition but less fit in terms of copepod grazing avoidance (Fig. 1; Table 1). Consequently, the contribution of bottom-up pressure to the fitness gradient is negative (i.e., it tends to decrease mean cell volume), whereas the contribution of top-down pressure is positive (i.e., it tends to increase mean cell volume; Fig. 6a). The balance between pressures determines whether the net fitness gradient is positive (selection for larger species; the resulting line is white in Fig. 6a) or negative (selection for smaller species; the resulting line is black in Fig. 6a). Early in the year, copepod biomass is low and bottom-up pressures prevail (Fig. 6a), allowing small-celled diatoms that maximize resource acquisition to thrive (up to day 100). Bottom-up and top-down pressures on cell volume both increase throughout spring up to day 150 , although with an interruption by Phaeocystis bloom (Fig. 6a). During the transition from the spring diatom bloom to a Phaeocystis-dominated system (after day 100), copepod grazing pressure increases. This affects diatom community biomass, but also its size structure: by preferring small prey, copepods select for larger diatoms. The balance between upward and downward selective forces between days 100 and 200 is alternate and then moderately dominated by top-down pressures (Fig. 6a), which leads to the maintenance of relatively small mean cell volumes $\left(\sim 10^{4} \mu \mathrm{m}^{3}\right)$ with a moderate increase (Fig. 4a). From day $\sim 200$, a slow-growing, more grazer controlled system emerges. In this phase, grazing pressures dominate (Fig. 6a), and the increase in size persists (Fig. 4a). This reverses only in early autumn (days 280-300) when the balance shifts to bottom-up pressures that select for smaller diatoms. This continues throughout the winter (Fig. 6a).

Figure $6 \mathrm{~b}$ shows the bottom-up and top-down pressures on the variance. Top-down pressure (i.e., grazing) tends to decrease variance, whereas bottom-up pressure (i.e., resource limitation) tends to favor higher diversity. Sink and source terms of the variance continuously balance each other over the year, with an overall trend in their intensity. In the beginning of the year (before day 50), pressures on the variance are reduced, and it reaches maximum levels (Figs. 4b, 6b). Bottom-up and top-down pressures then increase after the spring bloom (Fig. 6b), which results in increased selection pressure, steeper size-dependent growth and loss rates, and a narrower fitness peak. This causes a reduction in the diversity of the community (the variance is minimum around days 150-200; Fig. 4b). Reduced pressures in the second part of the year then allow more diversity to be sustained throughout autumn and winter 


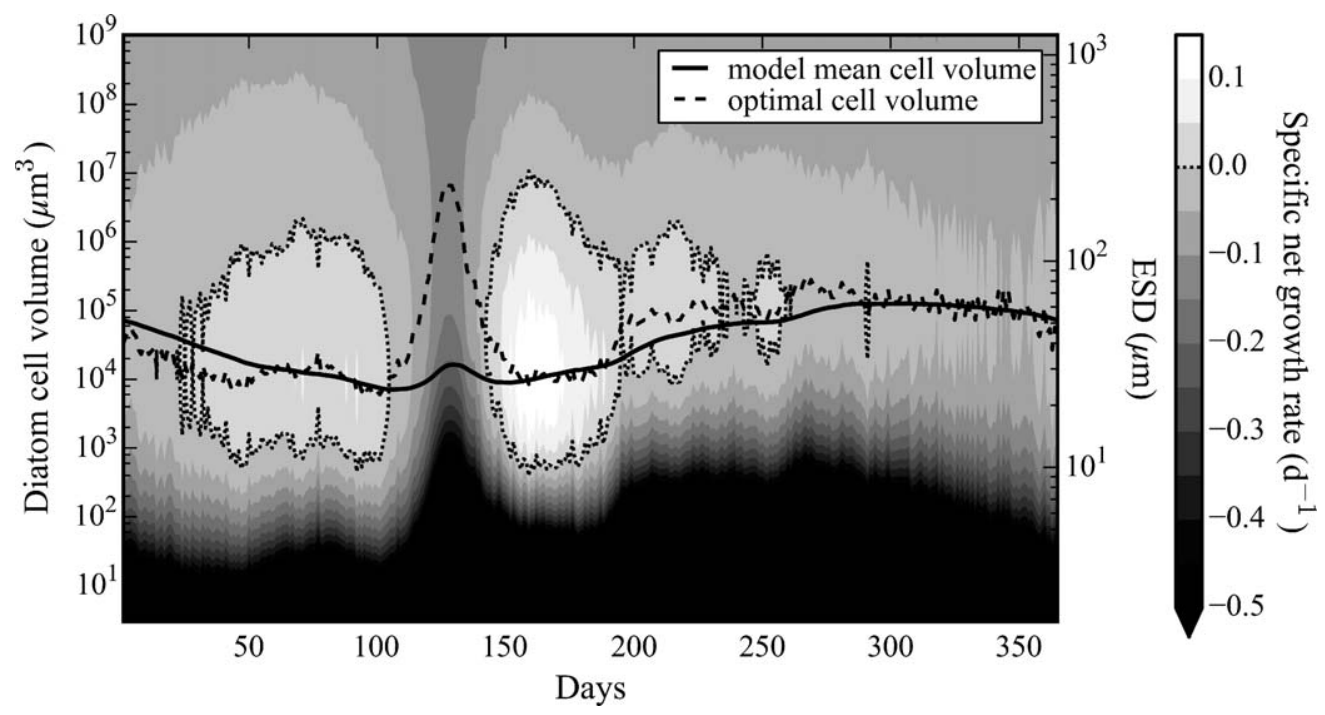

Fig. 7. Fitness landscape of diatoms in the BCZ: time evolution of the fitness of diatoms (specific net growth rate; grey scale) as a function of size (cell volume, left axis; ESD, right axis) in the simulated environment. Continuous line: simulated mean cell volume (see Fig. 4a); dashed line: simulated optimal cell volume. The areas inside the zero-growth isoclines (dotted lines) indicate a positive specific net growth rate.

(Figs. 4b, 6b). Altogether, the simulated pressures on the variance suggest that a higher diversity is sustained at the onset of the vegetative period and a lower diversity is reached in summer, as observed in other continental areas (Chang et al. 2003). It can be noted that the contribution of seeding diversity to the variance dynamics is significant and clearly indicates the need to restore variance through immigration processes to sustain diversity. The importance of exogenous diversity sources was pointed out before (Norberg et al. 2001, Bruggeman and Kooijman 2007) and constitutes a major challenge of new adaptive approaches.

\section{Discussion}

A size-based representation of diatom functional diversity has been introduced in an existing PFT model. In addition to capturing the time evolution of bulk diatom biomass, the new model properly describes the size structure of the diatom community in the BCZ: the spring bloom is composed of smaller species that maximize resource acquisition, and the summer diatom bloom includes larger species that resist copepod grazing. This seasonal pattern is due to the changing constraints on diatoms in terms of bottom-up and top-down factors. The BCZ indeed constitutes a continually changing environment hosting a limited number of adapted diatom species. In the next section, the developed model is exploited to determine the diatom ecological niche in the area. The framework used in this study, and relying on the size dependences of the main diatom traits, is then discussed in a broad ecological context.

Diatom community structure-The trait-based approach is convenient to help define the ecological niche of phytoplankton (Litchman et al. 2012) - here, in terms of positive net growth of diatoms of different size throughout time. This can be derived from Fig. 5: by evaluating the fitness (net growth) as a function of size, both the viable size range (hatched shaded area) and the optimal size (maximum) can be found. When plotted as a function of time, this produces an evolving fitness landscape (Fig. 7; i.e., the time evolution of the fitness [net growth rate] of diatoms of different sizes). Viable regions are bounded by isoclines of zero growth, shown as dotted lines (Fig. 7). These indicate two main periods in which a positive net growth may occur: from winter to spring (days 20-100) and in late spring-summer (days 140-260; results also hint at transient growth of narrow size ranges in autumn). These positive net growth regions allow the formation of two blooms, as supported by observations (Fig. 3a). Moreover, these two blooms favor species of different size: the spring bloom supports growth of species from 470 to $2 \times 10^{6} \mu \mathrm{m}^{3}$, with a maximum specific net growth rate at cell volumes around $10^{4} \mu \mathrm{m}^{3}$, whereas the second bloom allows larger species to thrive $\left(400-10^{7} \mu \mathrm{m}^{3}\right)$, with an optimal cell volume from $10^{4}$ to $>10^{5} \mu \mathrm{m}^{3}$. A shift in the optimal cell volume on order of magnitude $>1$ thus occurs around day 200, which is reflected in the lower mean cell volume of the spring bloom compared with that of the summer bloom in both data and model (Fig. 4a).

Zero-growth isoclines in Fig. 7 not only delimit the periods in which diatom positive net growth is possible, but also the size range for which the simulated environment may constitute a realized niche (i.e., the species achieving positive growth in the presence of competition and predation in the $\mathrm{BCZ}$; their persistence in the area despite unfavorable periods would be ensured, e.g., by sufficient population growth during favorable periods, resting stages, or immigration). The size range tested in the fitness landscape ( $y$ axis of Fig. 7) encompasses the entire $3 \mu \mathrm{m}^{3}$ 
to $>10^{9} \mu \mathrm{m}^{3}$ spectrum of diatom sizes observed in the global ocean (Leblanc et al. 2012). According to model predictions, species smaller than $400 \mu \mathrm{m}^{3}$ or larger than $\sim 10^{7} \mu \mathrm{m}^{3}$ do not experience positive growth at any moment of the year (Fig. 7). Beyond their import in the zone through physical processes (not taken into account in Fig. 7), they should hence not be observed in the BCZ. Strikingly, this predicted viable size range agrees fairly well with observations: the smallest and largest species found in the BCZ have a volume of $78 \mu \mathrm{m}^{3}(\sim 5 \mu \mathrm{m}$ equivalent spherical diameter, ESD) and $\sim 1.4 \times 10^{7} \mu \mathrm{m}^{3}(\sim 300 \mu \mathrm{m}$ ESD), respectively.

A more detailed analysis of predicted and observed diatom size ranges suggests that the model underestimates the viable size range at both ends. First, the model misses species $<400 \mu \mathrm{m}^{3}$ (9 $\mu \mathrm{m}$ ESD), while these are abundant in the area (e.g., Chaetoceros socialis, Skeletonema costatum). However, these small species actually form colonies (Rousseau et al. 2002), and some also exhibit siliceous setae (e.g., C. socialis), which may act as a deterrent against grazing (Hamm and Smetacek 2007). Both colony formation and deviations from spherical shape cause the functional size of a species, as relevant in the model (e.g., linear dimension for predation), to be greater than estimated from their measured individual cell volume. This may explain the mismatch between the observed and simulated minimum viable size. Alternatively, small diatoms may also be imported through immigration from the English Channel, which supports the growth of smaller species (Widdicombe et al. 2010).

At the upper end of the simulated viable size range, the model only briefly reaches $10^{7} \mu \mathrm{m}^{3}$ (Fig. 7). Although most observed large diatom cells are indeed closer to $10^{5}-10^{6} \mu \mathrm{m}^{3}$ (Rhizosolenia sp., Guinardia sp., and Coscinodiscus sp.), one very large species (Coscinodiscus pavillardii, $1.4 \times 10^{7} \mu \mathrm{m}^{3}$ ) is observed repeatedly in the area (especially in late summer). This suggests that the model may also underestimate the maximum viable size. Indeed, several factors are not accounted for in this size-based model that could actually favor larger species. First, bottom-up pressure could favor larger cells by selecting for nutrient storage capacity (Grover 1991), as was suggested by a theoretical model study in which larger diatoms were selected under pulsed N supply (Litchman et al. 2009). Silicate cannot be stored in large amounts in vacuoles (Martin-Jézéquel et al. 2000), but storage capacity might indeed constitute an advantage regarding phosphate. Second, lower susceptibility of larger diatoms to photoinactivation (Key et al. 2010) could favor large sizes at high light levels, as experienced by surface-dwelling diatoms in summer. However, this is unlikely to play a role in the well-mixed turbulent BCZ. Finally, while buoyancy control conferred on large species by their vacuole (Moore and Villareal 1996) could be beneficial in stratified waters, this is not likely to play a strong role in this well-mixed area.

The model may also underestimate the viable size range due to model features unrelated to diatom physiology. In particular, omission of mechanisms that in reality sustain diatom diversity could explain underestimation of the viable range at both ends of the size spectrum. One candidate for such a mechanism is the presence of a diverse grazer community. Although the dominant grazer (an average copepod with a fixed preference for each type of prey) is represented in the model, the wide range of diatom sizes in the BCZ (5-300 $\mu \mathrm{m}$ ESD) is not preyed upon by a single grazer: at the lower end, microzooplankton can exert grazing on in situ diatom blooms and were observed to consume prey up to $20 \mu \mathrm{m}$ (Strom et al. 2007); at the intermediate sizes, copepods at different stages in their life cycle possess different optimal prey sizes (Hansen et al. 1994), and at the upper end, large diatoms in the BCZ (Rhizosolenia sp., Guinardia sp.) are generally avoided by copepods (Antajan 2004) but consumed by the gelatinous dinoflagellate Noctiluca scintillans (Daro et al. 2008). The presence of grazers with different prey size preference would tend to flatten the size spectrum of the prey by disproportionate consumption of the most abundant size classes. This is confirmed by models: an adaptive zooplankton community (e.g., through the representation of multiple size classes) can create a refuge for otherwise less competitive species (Prowe et al. 2012). Similarly, the presence of a diverse size-selective grazer community was found to be a prerequisite for maintenance of a diverse phytoplankton community (Poulin and Franks 2010; Ward et al. 2012). These results suggest that inclusion of a community of grazers with different prey size preference, while beyond the scope of this study, has the potential to increase size diversity and thus increase the variance and viable size range in the present size-structured diatom model.

Altogether, the predicted $>4$ order of magnitude difference between the minimum and maximum viable diatom size is in good agreement with observations. The model also explains why other species are not present in the area. Smaller species would be excluded from the region by excessive grazing while their resource acquisition capacities are not sufficiently beneficial in this resource-replete environment. Thus, smaller diatoms would exist in areas where grazing is less critical or where resources are more limiting, providing them with increased advantage compared with the BCZ environment. For instance, smaller diatoms ( $\leq 10 \mu \mathrm{m}$ ESD) are commonly observed in ironlimited regions of the open ocean, but larger species (Rhizosolenia sp.; 10-100 $\mu \mathrm{m}$ ESD), similar in size to $\mathrm{BCZ}$ diatoms, are disproportionally favored when iron limitation is removed (Schartau et al. 2010). As in the present study, this could be linked to bottom-up and topdown control: half-saturation constants for $\mathrm{Fe}$ of diatoms correlate negatively with their surface-to-volume ratio (de Baar et al. 2005), while larger diatoms in the fertilized patch were suggested to thrive because they escape from grazing pressure by microzooplankton (Schartau et al. 2010). Returning to the $\mathrm{BCZ}$, large species $\left(>10^{7}\right.$ or $300 \mu \mathrm{m}$ ESD) excluded here might thrive in regions where large size offers additional benefits. Although nutrient storage, buoyancy control, or lower susceptibility to photoinactivation associated with large size offers few benefits in the eutrophic, well-mixed, and turbid BCZ, they could make a difference in other environments. For instance, the giant members of the largest known diatom genus, Ethmodiscus, 
are characteristic of the oligotrophic open ocean, where they exhibit vertical migration via buoyancy control between the nutricline and illuminated surface layer as part of their life cycle (Villareal et al. 1999). Similar control of vertical position also confers advantages on other large species of the genus Rhizosolenia (Richardson et al. 1996) and allows them to prosper in environments otherwise typically dominated by small phytoplankton. In conclusion, the very large and small diatom species are excluded from the enriched coastal area studied here, where the bottom-up and top-down constraints select for intermediately large species (centered around $10^{3}-10^{6} \mu \mathrm{m}^{3}$ or 10 $100 \mu \mathrm{m}$ ESD).

A size-based diatom model-How representative are the size dependences used in the model? Empirical allometric relationships for diatom functional traits $\left(\mu_{\max }, K_{\mathrm{NUT}}, \alpha\right.$, and $a f f_{\mathrm{DA}}^{\mathrm{CP}}$ ) were collected in the literature and included in an existing PFT model, keeping its trophic structure. The global pattern emerging from the gathered allometric relationships indicates a trade-off for diatoms along the bottom-up vs. top-down axis: small species are more competitive for resource acquisition $\left(\mu_{\max }, K_{\mathrm{NUT}}, \alpha\right)$, whereas larger diatoms are more able to escape from grazing pressure by copepods. This trade-off between growth and resistance to grazing was proposed before for marine and freshwater phytoplankton (Steiner 2003; Bruggeman 2011). This study hence conforms to the widely accepted idea that large sizes are favored by the presence of grazers (Smetacek 2001), as suggested by several modeling studies that underlined the importance of top-down pressure in structuring marine size structure and maintaining diversity (Armstrong 1994; Poulin and Franks 2010; Ward et al. 2012), although it does not rule out other advantages of large size (storage abilities, buoyancy control, or lower susceptibility to photoinactivation) in different environments. Likewise, the advantage of small cells in terms of resource acquisition is widely accepted and has been observed across many phytoplankton taxa (reviewed by Litchman and Klausmeier 2008; Edwards et al. 2012). While recent experiments hint at a nonmonotonic size dependence of $\mu_{\max }$ when considering a wide range of taxa (from cyanobacteria with $0.1 \mu \mathrm{m}^{3}$ cell volume to diatoms up to $10^{6} \mu \mathrm{m}^{3}$; Marañón et al. 2013), suggesting that allometric relationships are not universal, these still preserve the negative size scaling (i.e., small cell size advantage) within the diatoms. In this respect, the focus on a single PFT like diatoms is convenient to avoid nonmonotonic size dependence of functional traits or nonunimodal distribution of the community around a master trait (the cell volume in this study).

Overall, the trade-off described here (resource acquisition vs. mortality by grazing) associated with cell size may explain much of the variability in diatom size structure in natural environments. The observed succession in diatoms under a seasonally varying environment (BCZ: Rousseau et al. 2002; this study; other temperate marine systems: Widdicombe et al. 2010; Barton et al. 2013) would hence result from shifts in the relative importance of sizedependent processes in a time-varying environment, as showed in this study. Similarly but along spatial gradients, the relative importance of environmental controls of diatom size across different aquatic ecosystems was invoked to explain the distinct prevailing sizes under different physical regimes (Finkel et al. 2009). Succession in eutrophic waters typically starts with a vernal bloom under relatively high nutrient concentrations triggered by increased light availability, followed by a summer bloom under regenerated nutrients and increased grazing pressure (Sommer et al. 2012). During the initial bloom, small diatoms are favored by their higher intrinsic growth rate and benefit additionally from their higher photosynthetic efficiency during the initial, low-light phase of bloom development (Fig. 1a,c). Grazer abundance is still low, which implies that larger, slow-growing species have little advantage from their resistance to grazing. Increased presence of grazers following the spring bloom (Sommer et al. 2012) leads to a more important role for top-down control and an increase in diatom size. At this period of time, the relative advantage of small size would be counterbalanced by the necessity to escape from grazing by increasing cell size (or possibly to some extent, by the advantage of large nutrient-storing species; see above). A progressive transition from small to larger species can hence be expected to characterize diatom succession in eutrophic marine environments.

The predicted size succession within the diatom community contrasts with the canonical view of seasonal succession within all marine phytoplankton. In temperate waters, it is generally recognized that the spring bloom is characterized by a dominance of large phytoplankton (i.e., mostly diatoms), with the remainder of the year being governed by a continuous decrease in phytoplankton size (Malone 1980). This is primarily the result of the decreased dominance of diatoms, combined with their relatively large size among all phytoplankton - the model suggests that it does not reflect the small to large succession within the diatoms. In that sense, the present study pleads in favor of approaches to phytoplankton ecology that conserve the resolution of functional types, as they can have proper seasonal or spatial dynamics, with implications for the ecosystem functions such as carbon fixation and export or transfer to higher trophic levels.

In summary, size is a convenient attribute to constrain variability across several diatom functional traits. By linking size to function through empirical allometric relationships, the present model represents a key aspect of diatom diversity - variation in cell size - with a minimum of new free parameters. By further summarizing the size structure of the community in terms of key statistics (mean and variance of size), the model also achieves this in a computationally efficient manner. The measures of size represented in the model are directly linked to ecosystem functioning (e.g., food availability for secondary trophic levels) and are also readily compared with observations, as illustrated for the BCZ. Confidence in the size-based diatom model is further strengthened by its capacity to identify the viable diatom size range. This confirms the potential of the trait-based approach to the study of phytoplankton niches (Litchman et al. 2012). The trade- 
offs associated with diatom size are generic and potentially explain many spatial or temporal patterns in diatom community structure. Importantly, it includes top-down pressures as a preponderant force driving phytoplankton community structure, in contrast to earlier trait-based studies, which mainly rely on bottom-up factors to explain community structure patterns (Litchman et al. 2009; Edwards et al. 2013). Moreover, we suggest that the combination of PFT and trait-based approaches has a distinct benefit: by resolving diversity within a single type, typical caveats associated with trait-based approaches (e.g., nonmonotonic size-function relationships, multimodal size distributions) are avoided. Trait-based approaches can serve as a valuable tool to complement the classic PFT modeling approaches.

\section{Acknowledgments}

We are grateful to J.-Y. Parent and V. Rousseau for the sampling and measurement of the high-quality nutrients and diatom taxonomy and biometry used in this study. N.T. thanks G. Destree and R. Leplae for their support in the use of the computing facilities of the ULB-VUB. We thank two anonymous reviewers for their constructive comments.

N.T. received financial support from the "Fonds pour la formation à la Recherche dans l'Industrie et dans l'Agriculture" (F.R.I.A., Belgium) and the "Fonds David et Alice Van Buuren." The work of J.B. was supported by a Junior Research Fellowship at St. John's College, Oxford. Computational resources have been provided by CÉCI, funded by the Fonds de la Recherche Scientifique de Belgique (F.R.S.-FNRS) under grant 2.5020.11 and by the Computing Centre High Performance Computing of ULB-VUB.

\section{References}

Aksnes, D., And J. Egge. 1991. A theoretical model for nutrient uptake in phytoplankton. Mar. Ecol. Prog. Ser. 70: 65-72, doi: $10.3354 /$ meps070065

Antajan, E. 2004. Responses of calanoid copepods to changes in phytoplankton dominance in the diatom/Phaeocystis globosa dominated Belgium coastal waters. Ph.D. thesis. Vrije Univ. van Brussel.

Armstrong, R. A. 1994. Grazing limitation and nutrient limitation in marine ecosystems: Steady state solutions of an ecosystem model with multiple food chains. Limnol. Oceanogr. 39: 597-608, doi:10.4319/lo.1994.39.3.0597

Baretta, J., W. Ebenhöh, and P. Ruardi. 1995. The European regional seas ecosystem model, a complex marine ecosystem model. J. Sea Res. 33: 233-246, doi:10.1016/0077-7579(95) 90047-0

Barton, A. D., Z. V. Finkel, B. A. Ward, D. G. Johns, and M. J. Follows. 2013. On the roles of cell size and trophic strategy in North Atlantic diatom and dinoflagellate communities. Limnol. Oceanogr. 58: 254-266, doi:10.4319/lo.2013.58.1.0254

Boyd, P., AND P. Newton. 1995. Evidence of the potential influence of planktonic community structure on the interannual variability of particulate organic carbon flux. Deep-Sea Res. I 42: 619-639, doi:10.1016/0967-0637(95)00017-Z

BRugGeman, J. 2011. A phylogenetic approach to the estimation of phytoplankton traits. J. Phycol. 47: 52-65, doi:10.1111/ j.1529-8817.2010.00946.x

, AND S.A.L.M. KoOIJMAn. 2007. A biodiversity-inspired approach to aquatic ecosystem modeling. Limnol. Oceanogr. 52: 1533 , doi:10.4319/lo.2007.52.4.1533
Chang, F. H., J. Zeldis, M. Gall, and J. Hall. 2003. Seasonal and spatial variation of phytoplankton assemblages, biomass and cell size from spring to summer across the north-eastern New Zealand continental shelf. J. Plankton Res. 25: 737-758, doi:10.1093/plankt/25.7.737

Chesson, P. 2000. Mechanisms of maintenance of species diversity. Annu. Rev. Ecol. Syst. 31: 343-366, doi:10.1146/ annurev.ecolsys.31.1.343

Daro, M.-H., E. Breton, E. Antajan, S. Gasparini, and C. LANCElot. 2008. Do Phaeocystis colony blooms affect zooplankton in the Belgian coastal zone? p. 61-72. In V. Rousseau, C. Lancelot, and D. Cox [eds.], Current status of eutrophication in the Belgian coastal zone. Presses Univ. de Bruxelles.

DE BAAR, H. J., AND others. 2005. Synthesis of iron fertilization experiments: From the Iron Age in the Age of Enlightenment. J. Geophys. Res. 110: C09S16, doi:10.1029/2004JC002601

Edwards, K. F., E. Litchman, and C. A. Klausmeier. 2013. Functional traits explain phytoplankton community structure and seasonal dynamics in a marine ecosystem. Ecol. Lett. 16: 56-63, doi:10.1111/ele.12012

- M. K. Thomas, C. A. Klausmeier, and E. Litchman. 2012. Allometric scaling and taxonomic variation in nutrient utilization traits and maximum growth rate of phytoplankton. Limnol. Oceanogr. 57: 554-566, doi:10.4319/1o.2012.57.2. 0554

FinkeL, Z. V. 2001. Light absorption and size scaling of lightlimited metabolism in marine diatoms. Limnol. Oceanogr. 46: 86-94, doi:10.4319/1o.2001.46.1.0086

- J. Beardall, K. J. Flynn, A. Quigg, T. A. V. Rees, And J. A. Raven. 2010. Phytoplankton in a changing world: Cell size and elemental stoichiometry. J. Plankton Res. 32: 119-137, doi:10.1093/plankt/fbp098

, C. J. Vaillancourt, A. J. Irwin, E. D. Reavie, and J. P. SMOL. 2009. Environmental control of diatom community size structure varies across aquatic ecosystems. Proc. R. Soc. Lond. B 276: 1627-1634, doi:10.1098/rspb.2008.1610

Follows, M. J., S. Dutkiewicz, S. Grant, and S. W. Chisholm. 2007. Emergent biogeography of microbial communities in a model ocean. Science 315: 1843-1846, doi:10.1126/ science. 1138544

Gismervik, I., T. Andersen, and O. Vadstein. 1996. Pelagic food webs and eutrophication of coastal waters: Impact of grazers on algal communities. Mar. Pollut. Bull. 33: 22-35, doi: 10.1016/S0025-326X(96)00134-8

Grover, J. P. 1991. Resource competition in a variable environment: Phytoplankton growing according to the variable-internal-stores model. Am. Nat. 138: 811-835, doi:10.1086/285254

Gypens, N., G. Lacroix, and C. Lancelot. 2007. Causes of variability in diatom and Phaeocystis blooms in Belgian coastal waters between 1989 and 2003: A model study. J. Sea Res. 57: 19-35, doi:10.1016/j.seares.2006.07.004

Hamm, C., And V. Smetacek. 2007. Armor: Why, when, and how, p. 311-332. In P. Falkowski and A. Knoll [eds.], Evolution of primary producers in the sea. Elsevier.

Hansen, B., P. K. Buørnsen, and P. J. Hansen. 1994. The size ratio between planktonic predators and their prey. Limnol. Oceanogr. 39: 395-403, doi:10.4319/lo.1994.39.2.0395

Hood, R. R., AND others. 2006. Pelagic functional group modeling: Progress, challenges and prospects. Deep-Sea Res. II 53: 459-512, doi:10.1016/j.dsr2.2006.01.025

Key, T., A. McCarthy, D. A. Campbell, C. Six, S. Roy, and Z. V. Finkel. 2010. Cell size trade-offs govern light exploitation strategies in marine phytoplankton. Environ. Microbiol. 12: $95-104$, doi:10.1111/j.1462-2920.2009.02046.x 
Kiørboe, T. 2011. How zooplankton feed: Mechanisms, traits and trade-offs. Biol. Rev. 86: 311-339, doi:10.1111/j.1469-185X. 2010.00148.x

Lancelot, C., N. Gypens, G. Billen, J. Garnier, and V. Roubeix. 2007. Testing an integrated river-ocean mathematical tool for linking marine eutrophication to land use: The Phaeocystis-dominated Belgian coastal zone (Southern North Sea) over the past 50 years. J. Mar. Syst. 64: 216-228, doi:10.1016/j.jmarsys.2006.03.010

—, AND OTHERs. 2005. Modelling diatom and Phaeocystis blooms and nutrient cycles in the Southern Bight of the North Sea: The MIRO model. Mar. Ecol. Prog. Ser. 289: 63-78, doi:10.3354/meps289063

Le QuÉRÉ, C. L., AND OTHERs. 2005. Ecosystem dynamics based on plankton functional types for global ocean biogeochemistry models. Glob. Change Biol. 11: 2016-2040, doi:10.1111/ j.1365-2486.2005.1004.x

Leblanc, K., And others. 2012. A global diatom databaseabundance, biovolume and biomass in the world ocean. Earth Syst. Sci. Data 4: 149-165, doi:10.5194/essd-4-149-2012

Litchman, E., K. F. Edwards, C. A. Klausmeier, and M. K. Thомаs. 2012. Phytoplankton niches, traits and eco-evolutionary responses to global environmental change. Mar. Ecol. Prog. Ser. 470: 235-248, doi:10.3354/meps09912

—, And C. A. Klausmeier. 2008. Trait-based community ecology of phytoplankton. Annu. Rev. Ecol. Evol. Syst. 39: 615-639, doi:10.1146/annurev.ecolsys.39.110707.173549

, O. M. Schofield, and P. G. Falkowski. 2007. The role of functional traits and trade-offs in structuring phytoplankton communities: Scaling from cellular to ecosystem level. Ecol. Lett. 10: 1170-1181, doi:10.1111/j.1461-0248. 2007.01117.x

evolution in marine and freshwater diatoms. Proc. Natl. Acad. Sci. USA 106: 2665, doi:10.1073/pnas.0810891106

Malone, T. C. 1980. Size-fractionated primary productivity of marine phytoplankton, p. 301-319. In P. G. Falkowski [ed.], Primary productivity in the sea. Plenum Press.

Marañón, E., P. Cermeño, J. Rodríguez, M. V. Zubkov, and R. P. Harris. 2007. Scaling of phytoplankton photosynthesis and cell size in the ocean. Limnol. Oceanogr. 52: 2190-2198, doi: $10.4319 /$ lo. 2007.52 .5 .2190

— , AND OTHERS. 2013. Unimodal size scaling of phytoplankton growth and the size dependence of nutrient uptake and use. Ecol. Lett. 16: 371-379, doi:10.1111/ele.12052

Martin-Jézéquel, V., M. Hildebrand, and M. A. Brzezinski. 2000. Silicon metabolism in diatoms: Implications for growth. J. Phycol. 36: 821-840, doi:10.1046/j.1529-8817.2000. 00019.X

McQuoid, M. R., AND A. GodHe. 2004. Recruitment of coastal planktonic diatoms from benthic versus pelagic cells: Variations in bloom development and species composition. Limnol. Oceanogr. 49: 1123-1133, doi:10.4319/1o.2004.49.4.1123

Menden-Deuer, S., and E. J. Lessard. 2000. Carbon to volume relationships for dinoflagellates, diatoms, and other protist plankton. Limnol. Oceanogr. 45: 569-579, doi:10.4319/ lo.2000.45.3.0569

Merico, A., J. Bruggeman, And K. Wirtz. 2009. A trait-based approach for downscaling complexity in plankton ecosystem models. Ecol. Model. 220: 3001-3010, doi:10.1016/j.ecolmodel. 2009.05.005

Montagnes, D. J. S., J. A. Berges, P. J. Harrison, and F. TAYLOR. 1994. Estimating carbon, nitrogen, protein, and chlorophyll $a$ from volume in marine phytoplankton. Limnol. Oceanogr. 39: 1044-1060, doi:10.4319/1o.1994.39.5.1044
Moore, J., And T. Villareal. 1996. Buoyancy and growth characteristics of three positively buoyant marine diatoms. Mar. Ecol. Prog. Ser. 132: 203-213, doi:10.3354/ meps 132203

Norberg, J., D. P. Swaney, J. Dushoff, J. Lin, R. Casagrandi, AND S. A. Levin. 2001. Phenotypic diversity and ecosystem functioning in changing environments: A theoretical framework. Proc. Natl. Acad. Sci. USA 98: 11376-11381, doi:10.1073/pnas. 171315998

PAasche, E. 1973. Silicon and the ecology of marine plankton diatoms. I. Thalassiosira pseudonana (Cyclotella nana) grown in a chemostat with silicate as limiting nutrient. Mar. Biol. 19: 117-126, doi:10.1007/BF00353582

Poulin, F. J., AND P. J. S. Franks. 2010. Size-structured planktonic ecosystems: Constraints, controls and assembly instructions. J. Plankton Res. 32: 1121-1130, doi:10.1093/ plankt/fbp145

Prowe, A. E. F., M. Pahlow, S. Dutkiewicz, M. Follows, and A. Oschlies. 2012. Top-down control of marine phytoplankton diversity in a global ecosystem model. Prog. Oceanogr. 101: 1-13, doi:10.1016/j.pocean.2011.11.016

Richardson, T. L., A. M. Ciotti, J. J. Cullen, and T. A. Villareal. 1996. Physiological and optical properties of Rhizosolenia formosa (Bacillariophyceae) in the context of open-ocean vertical migration. J. Phycol. 32: 741-757, doi:10.1111/j.0022-3646.1996.00741.x

Rousseau, V., A. Leynaert, N. Daoud, and C. Lancelot. 2002. Diatom succession, silicification and silicic acid availability in Belgian coastal waters (Southern North Sea). Mar. Ecol. Prog. Ser. 236: 61-73, doi:10.3354/meps236061

, AND OTHERS. 2004. Identification of Belgian maritime zones affected by eutrophication (IZEUT): Towards the establishment of ecological criteria for the implementation of the OSPAR Common Procedure to combat eutrophication. Belgian Science Policy Publications, Brussels, D/2004/1191/ 28.

Sarthou, G., K. R. Timmermans, S. Blain, and P. Tréguer. 2005. Growth physiology and fate of diatoms in the ocean: A review. J. Sea Res. 53: 25-42, doi:10.1016/j.seares.2004. 01.007

Schartau, M., M. R. Landry, And R. A. Armstrong. 2010. Density estimation of plankton size spectra: A reanalysis of IronEx II data. J. Plankton Res. 32: 1167-1184, doi:10.1093/plankt/fbq072

SMetAceK, V. 2001. A watery arms race. Nature 411: 745-745, doi:10.1038/35081210

Smith, R. J. 2009. Use and misuse of the reduced major axis for line-fitting. Am. J. Phys. Anthropol. 140: 476-486, doi:10.1002/ajpa.21090

Sommer, U., And others. 2012. Beyond the Plankton Ecology Group (PEG) model: Mechanisms driving plankton succession. Annu. Rev. Ecol. Evol. Syst. 43: 429-448, doi:10.1146/ annurev-ecolsys-110411-160251

Steiner, C. F. 2003. Keystone predator effects and grazer control of planktonic primary production. Oikos 101: 569-577, doi:10.1034/j.1600-0706.2003.12309.x

Storn, R., AND K. Price. 1997. Differential evolution-a simple and efficient heuristic for global optimization over continuous spaces. J. Glob. Optim. 11: 341-359, doi:10.1023/A:1008202821328

Strom, S. L., E. L. Macri, and M. B. Olson. 2007. Microzooplankton grazing in the coastal Gulf of Alaska: Variations in top-down control of phytoplankton. Limnol. Oceanogr. 52: 1480, doi:10.4319/1o.2007.52.4.1480

TAGUCHI, S. 1976. Relationship between photosynthesis and cell size of marine diatoms. J. Phycol. 12: 185-189, doi:10.1111/ j.1529-8817.1976.tb00499.x 
Villareal, T. A., L. Joseph, M. A. Brzezinski, R. F. Shipe, F. Lipschultz, And M. A. Altabet. 1999. Biological and chemical characteristics of the giant diatom Ethmodiscus (Bacillariophyceae) in the central North Pacific gyre. J. Phycol. 35: 896-902, doi:10.1046/j.1529-8817.1999.3550896.x

Ward, B. A., S. Dutkiewicz, O. Jahn, And M. J. Follows. 2012. A size-structured food-web model for the global ocean. Limnol. Oceanogr. 57: 1877-1891, doi:10.4319/1o.2012.57.6.1877

Widdicombe, C. E., D. Eloire, D. Harbour, R. P. Harris, and P. J. Somerfield. 2010. Long-term phytoplankton community dynamics in the western English Channel. J. Plankton Res. 32: 643-655, doi:10.1093/plankt/fbp127
Wirtz, K.-W., AND B. EcKhardt. 1996. Effective variables in ecosystem models with an application to phytoplankton succession. Ecol. Model. 92: 33-53, doi:10.1016/03043800(95)00196-4

Associate editor: Thomas R. Anderson

Received: 13 March 2014 Accepted: 14 July 2014 Amended: 23 July 2014 